\title{
The Student Elevator Pitch Is Dead, Long Live the Student Elevator Pitch
}

\author{
Kevin Ernst \\ Ohio Northern University
}

The social distancing and state mandated shutdowns of 2020 brought challenges to spring semester for colleges use to in person instruction. For the most part, these challenges were met with innovation and readily accepted, or accepted as sufficient given the challenges, or outright rejected. This led to research into to the teaching methodologies and desired educational outcomes of Elevator Pitches. This paper looks at the desired educational outcome and how participants feel the outcome was met via the educational tools employed, such as a student elevator pitch competition. This paper also identifies outcomes that can be achieved when students' employee certain marketing concepts in the design of their elevator pitch.

Keywords: Student Elevator Pitch

\section{INTRODUCTIONS}

The social distancing and state mandated shutdowns of 2020 brought challenges to spring semester for colleges use to in person instruction. For the most part, these challenges were met with innovation and readily accepted, or accepted as sufficient given the challenges, or outright rejected. One such change made by the author to meet the challenge of students being off campus was the Polar Elevator Pitch Competition. The Pitch, as it's come to be known around campus, is a run of the mill student competition where teams of students develop a new business idea and then have 2-minutes to present their idea to a panel of judges. To accommodate for students, and judges, now being off campus and unable to be in the same room with each other, the author converted the Pitch to a Kickstarter type activity where the student created a video of their business idea showcasing its benefits, uses, and then discussed the video and implications of their idea with judges via Google Meeting. The judges then picked a first, second, and third place winner out of the contestants.

Leading up to and even after the Pitch, this author received quite a few well thought out concerns and reasons why something other than a traditional elevator pitch should not be used as well as an almost equal show of support. This led to research into to the teaching methodologies and desired educational outcomes of Elevator Pitches, or in a simpler way of putting it, "why are we doing this and what are our students getting out of it!"

\section{BACKGROUND}

The Polar Elevator Pitch competition held each semester at Ohio Northern University's James F. Dicke College of Business Administration is similar to other competitions held at other institutions of higher education and even some community entrepreneurship centers. A quick Google search for "elevator pitch 
competition" quickly identified other school's programs and details about their events. Statements about the event from a select few are as follows: "Students hone their skills through events like the Polar Elevator Pitch Competition, where they have two minutes to sell their idea to a panel of faculty, students and members of the local business community." (Ohio Northern University); "An Elevator Pitch is a quick way of putting across the fundamental elements of a project, a business idea, a social cause or even one's professional qualifications and capturing the other person's attention to prompt him/her to action." (John Cabot University); "An elevator pitch or elevator speech is a short (30-90 second) personal statement that summarizes who you are, what you know and what you want to do. The ideal elevator pitch will leave the person you are speaking with impressed and wanting to learn more about you. A well-crafted and delivered elevator pitch is a useful tool that you can use in any number of situations from chance meetings to career fairs to job interview introductions." (Wayne State University); "An elevator pitch of 90 seconds or less is intended to 'sell' your ideas and skillset to a potential employer, decision maker, or influencer. You only need to provide enough details during the presentation to entice your audience to meet with you again for a more detailed conversation. In other words, you want to compel the audience to bring you back for a further conversation." (ASME Engineering Festivals); "The event is patterned on a national competition and teaches students the importance of presenting a "big idea" as succinctly and convincingly as possible." (Champlain College).

Whereas the "idea" is always present in these competitions, there is an emphasis on the ability to verbally sell or convince the audience that the idea is worthy of continued discussion. A phenomenon noted by the author during the 2020 spring Polar Elevator Pitch video presentations was that the idea sold itself. The adage, "a picture is worth a thousand words", would sum up this phenomenon. From this recognition that videos depicting the use of the idea or showing the benefit of the idea where clearly being chosen over the participant's verbal sell of the idea, the author contemplated the fairness of the event and the fairness of the traditional elevator pitch.

The inequality created from a video version, or as most participating in the event referred to; a kickstarterish type video, was that not all students had access to video equipment, editing software, nor expertise in filmmaking. This point was argued by several faculty members whose student teams did not fare well in the competition. There was also concern on the part of some faculty that they did not feel comfortable with technology that students were finding and using to achieve the video or the process of creating videos in general and therefore could not help their students expertly as they could a verbal pitch.

But, in contemplation of the traditional elevator pitch, this author argues that most institutions of higher education are creating inequality in the event through the topics taught and the prerequisites, or rather lack of prerequisites, of the course in which the event is initiated. Taking a look at the 4 main courses; Principles of Entrepreneurship, Legal Environment, Introduction to Engineering 2, and Product Design \& Innovation; the course topics taught do not include verbal communications or public speaking. Rather, there are specific general education courses that cover these topics. Principles of Entrepreneurship and Introduction to Engineering 2 are primarily freshman classes and the others are upper level courses. It can be argued that the freshman students have not all had a speech or communications type course prior to taking the classes in which they will be asked to compete in an elevator pitch, whereas the other courses should have most of their students through the general education speech courses. This author, along with other faculty members, teaches Principles of Entrepreneurship and has of recently recruited a faculty member from the theatre department to give a one-day lesson on presenting in an attempt to level the playing field. Prior to this, preparation of the students for their speaking roles was done via video examples and practice with feedback in the classroom.

\section{METHODS}

A survey of contestants of the spring 2020 Polar Elevator Pitch competition, faculty involved with the competition, judges used for the competition, and students used in an administrative role during the competition was analyzed. The survey was IRB approved. A search of peer-reviewed literature via Business Source Complete using the key words (elevator pitch) AND (kickstarter AND teaching) AND (persuasive 
communication AND remote) AND (persuasive communication AND video) with not limit on publication date was performed. Inclusion criteria included primary literature written in English and articles that described methodologies of teaching or use of the topic. The title and abstract of each article was screened, and the full-text of articles identified as relevant to the research being conducted were independently reviewed to determine inclusion.

There were 1,302 articles identified through the use of the search terms. The largest results, search term "kickstarter", were refined with a secondary search term of "teaching" and identified 15 articles. Of the 164 articles identified using the search term "elevator pitch", 2 were negative towards the idea of an elevator pitch and the rest focused on the functional aspect of pitching and readily stated what seems to be a common acceptance that one's ability to gain and hold another attention quickly will lead to better things to come. During the research of the "kickstarter" articles, the author found an article titled "Persuasion in crowdfunding: An elaboration likelihood model of crowdfunding performance" published recently in the Journal of Business Venturing by Thomas H. Allison, Blakley C. Davis, Justin W. Webb, and Jeremy C. Short. This article focused on the elaboration likelihood model (ELM) of persuasion identified by Petty and Cacioppo (1986) to examine how crowdfunding entrepreneurs persuade others to provide capital through the use of "issue-relevant information and peripheral cues" (Allison, et al 2017). The study's results suggest that the extent to which persuasion is primarily driven by issue-relevant information or peripheral cues is contingent upon funders' motivation and ability.

Focusing on the keyword "ability", additional research was conducted on the ability to persuade and 2 articles were identified using the search terms "persuasive communication" and "remote" in business source complete along with 26 using the search terms "persuasive communication" and "video" in business source complete.

\section{RESULTS}

60 responses were obtained and used in the final analysis ( $21.5 \%$ response rate). $61.67 \%$ of respondents were contestants; $31.67 \%$ were judges; $5 \%$ were faculty member or advisor to a contestant; $0 \%$ were administrative support for the event; and $1.67 \%$ were other. 207 articles were identified and considered for inclusion based on reviews of abstract. 51 articles were selected for consideration in a full-text review. Of these articles, 18 met inclusion criteria and were categorized into four overarching categories (elevator pitch $[n=9]$, kickstarter + teaching $[n=4]$, persuasive communication + remote $[n=1]$, and persuasive communication + video $[\mathrm{n}=4])$.

\section{IMPLICATIONS}

The survey determined that participants of the spring 2020 Polar Elevator Pitch competition preferred the pre-recorded video aspect of the event as well as the ability to meet with their judges to discuss the video. The literature review found that there are many articles written on how to create an elevator pitch with few offering proof that an elevator pitch works to secure funding and or persuade an audience member. However, articles that dealt with Kickstarter and other crowdsource funding had much data proving the success of the model. Additionally, both options offered little scientific data to prove why they work as tools of persuasion. However, one article evaluated the concept of Elaboration Likelihood Model (ELM) of persuasion (Petty and Cacioppo, 1986) on users of the crowdfunding source Kickstarter (Allison, Davis, Webb, and Short, 2017), which may prove useful for preparing students for Elevator Pitch competition or alternative forms of business idea persuasion events.

\section{CONCLUSIONS}

Experiential learning and modern educational practices place a premium on experience based outcomes and seem to force educators toward practical use as an outcome for their students. Through the research conducted on this topic, this author believes persuasion to be a skill worth of teaching students. The question 
yet to be answered is "what is the best way for an entrepreneur to reach their audience?" The use of the in person elevator pitch is tried and true and so readily accepted that it's methods and outcomes are rarely questioned; and the use video depicting the business idea as a replacement to the elevator pitch is so new that it lacks empirical data to prove or disprove it.

A review of peer-reviewed literature focused on elevator pitches and the use of video in crowdfunding did not provide sufficient evidence to conclude which method is advantageous nor which is preferred over the other. An analysis of the survey conducted after the spring 2020 Polar Elevator Pitch competition found that most participants (results comprise of student and judge without distinction as to which they are) do not want an event where only a video is submitted and there is no live interaction with each other. The analysis also found that the traditional person elevator pitch was preferred although the use of a video to introduce the product followed by an in person meeting was a close second (figure 6). Looking at two specific questions asked of the participants, Q5-figure3 and Q14-figure4, it is clear that an educational outcome needs to be the student's ability to present in person unscripted. However, the participants also recognize that persuasion can occur from a non-live and scripted method. It is therefore the author's conclusion that additional research is necessary to determine which method yields the most favorable and predictable outcomes and methods to ensure that students are equipped with the skills to facilitate those methods be identified.

\section{REFERENCES}

Allison, T., Davis, B., Webb, J., \& Short, J. (2017). Persuasion in crowdfunding: An elaboration likelihood model of crowdfunding performance. Journal of Business Venturing, 32, 707-725.

ASME E-FESTS. (n.d.). Elevator Pitch Competition. Retrieved January 10, 2021, from https://efests.asme.org/competitions/elevator-pitch-competition-new

Champlain College. (n.d.). Elevator Pitch Competition. Retrieved January 10, 2021, from https://www.champlain.edu/career-success/career-collaborative/career-events/elevator-pitchcompetition

John Cabot. (n.d.). Elevator pitch competition - rules. Retrieved January 10, 2021, from https://www.johncabot.edu/entrepreneurship-institute/EP\%20Rules\%20and\%20Regulations.pdf

Ohio Northern University. (n.d.). Entrepreneurship opportunities. Retrieved January 10, 2021, from https://www.onu.edu/academics/entrepreneurship

Wayne State University. (n.d.). Elevator Pitch Competition. Retrieved January 10, 2021, from https://ilitchbusiness.wayne.edu/resources/elevator.php 


\section{APPENDIX}

\section{FIGURE 1 \\ QUESTION REGARDING THE ABILITY TO MEET THE EDUCATIONAL OBJECTIVES OF EFFECTIVELY COMMUNICATING VALUE, NEEDS, AND PLANS VIA A REMOTE EXPERIENCE}

Q3 - Considering the traditional method of achieving this where students present a scripted speech and or act out a scripted skit in real-time explaining the benefits of the product/service with a panel of judges in the same physical space as the presenters; please score your thoughts/opinions below:

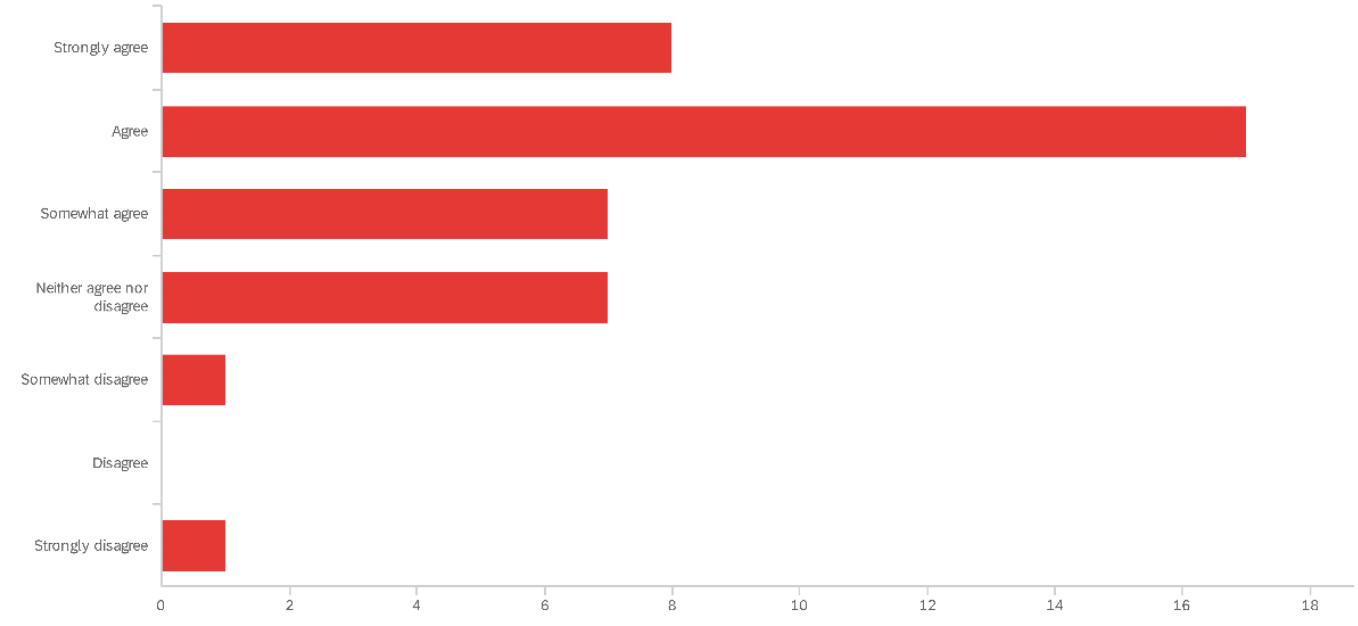




\section{FIGURE 2 \\ QUESTION TO DETERMINE THE RESPONDENT'S ACCEPTANCE OF NON-FACE-TO- FACE INTERACTIONS}

Q4 - Considering the recent trends in crowdsourcing and the prevalence of media platforms such as YouTube and Vimeo that allow startup companies to achieve the functional objectives mentioned earlier by video recording and sharing a scripted speech and or acting out a scripted skit showcasing the benefits of the product/service for investors and clients to review at their leisure, please score your agreement that this is the preferred method for startup companies to employ to secure funding/backing of their products/services.

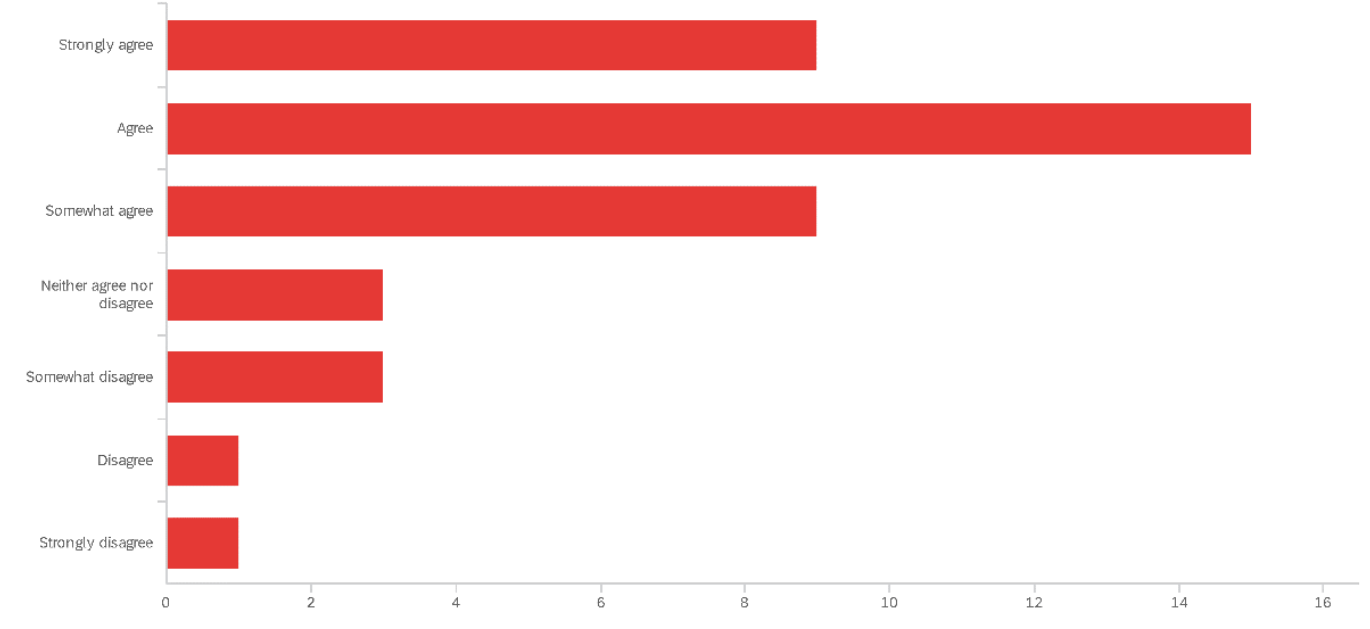




\section{FIGURE 3 \\ QUESTION TO DETERMINE THE RESPONDENT'S STANCE ON REMOTE VS FACE-TO- FACE INFORMATION DISSEMINATION}

Q5 - Please rank your opinion with the following statement: "The experience for students to be able to and prepared to communicate information once (live) without multiple opportunities (recorded) to ensure the information is effective, of value, and meets the needs of their audience is a valuable skill."

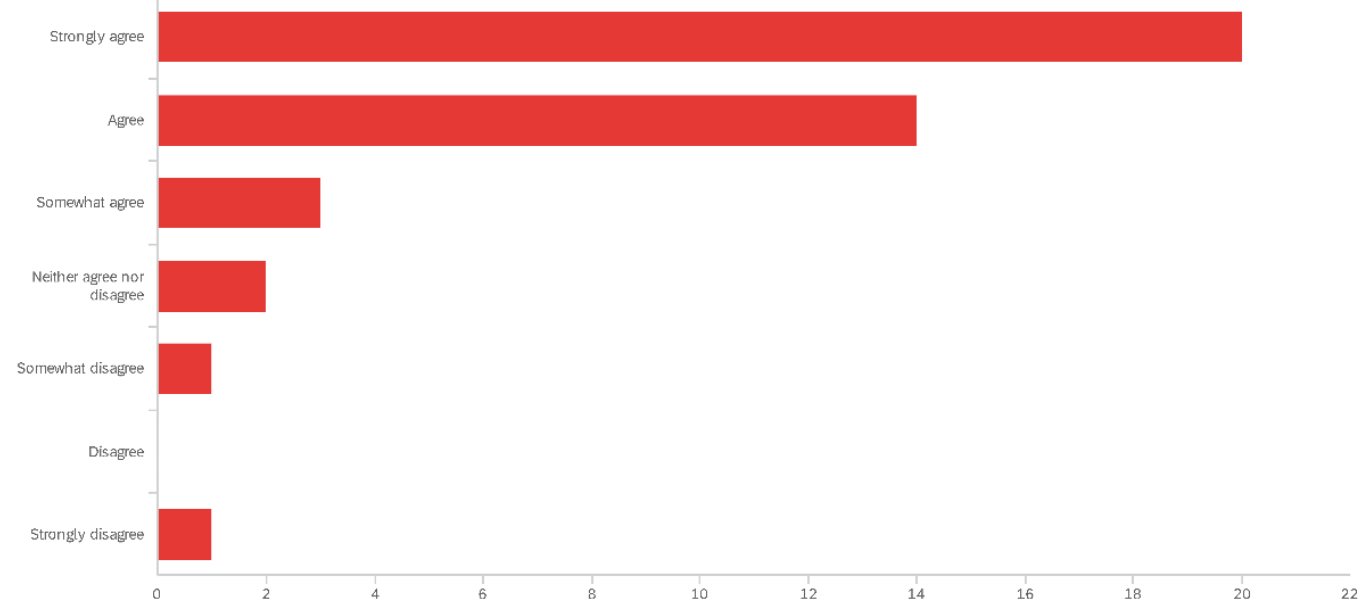




\section{FIGURE 4}

\section{QUESTION TO DETERMINE THE RESPONDENT'S PREFERENCE OF OBTAINING}

DECISION MAKING INFORMATION

Q14 - From the perspective of making decisions, how comfortable are you with making a decision based upon being told about the product/service (ie choosing to watch a movie based upon watching the trailer)?

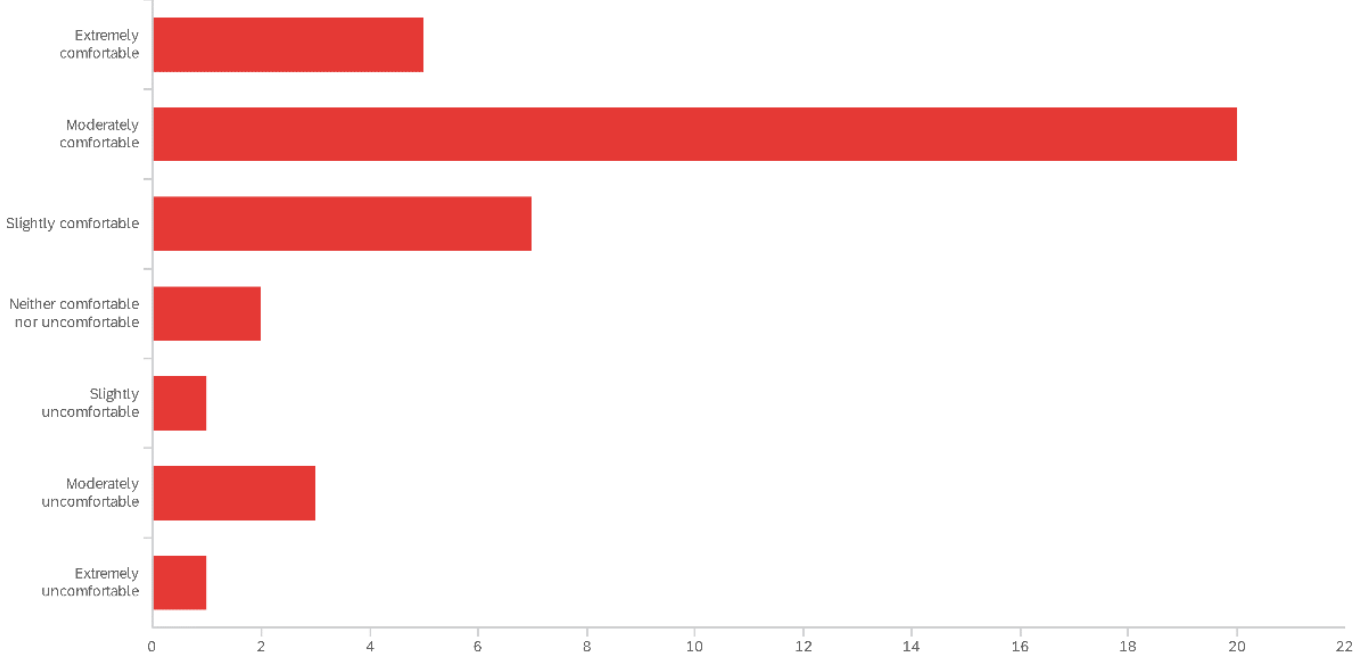

FIGURE 5

\section{QUESTION TO DETERMINE ACCEPTANCE RATE OF THE PROCESS IN QUESTION}

Q16 - If you were asked to participate in an event with the same parameters as this semester's Polar Elevator Pitch competition, how likely are you to want to participate?

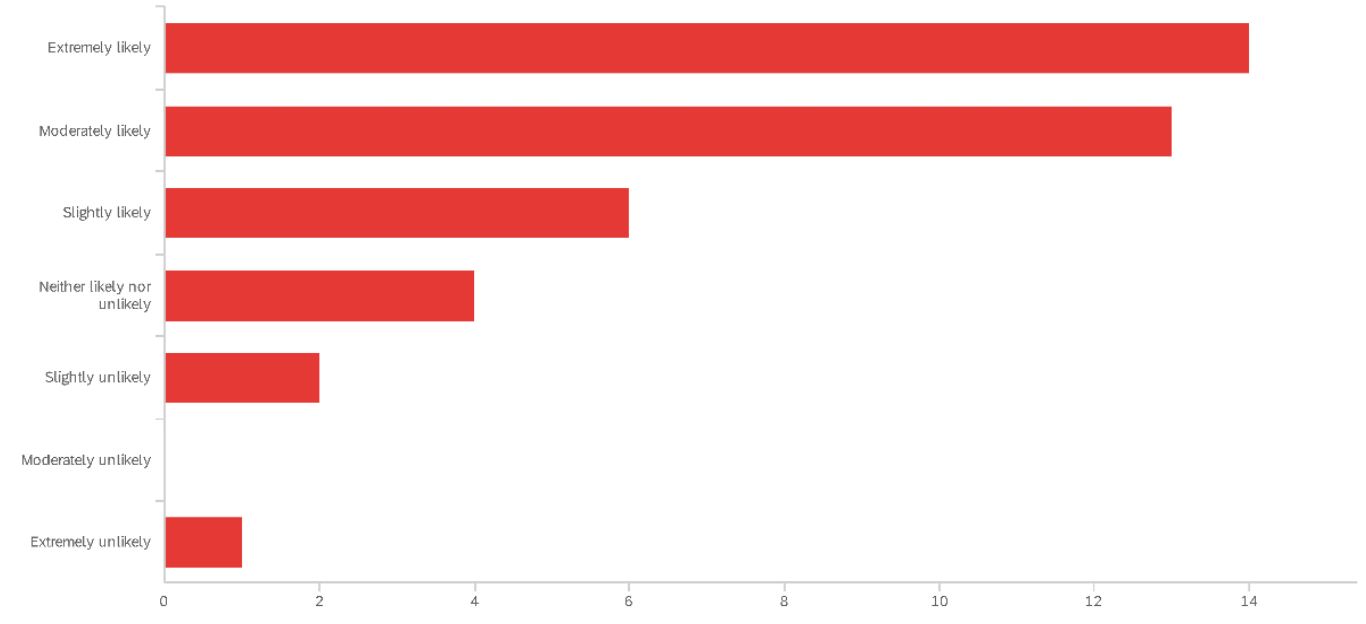




\section{FIGURE 6 \\ QUESTION TO DETERMINE THE PREFERENCE OF THE RESPONDENT}

Q17 - Please rank your preference for the structure of future Polar Elevator Pitch

competitions:

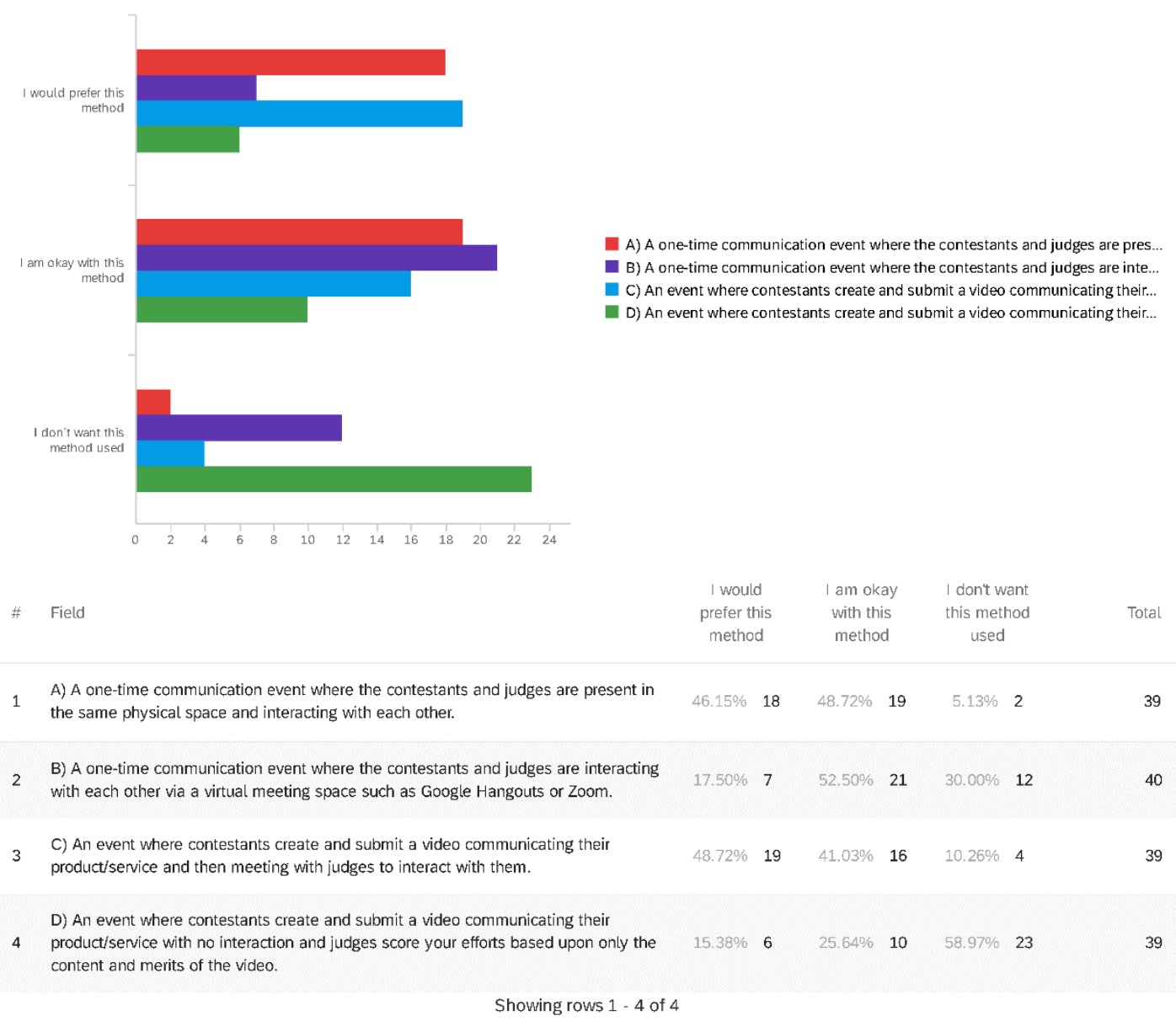

164 Journal of Higher Education Theory and Practice Vol. 21(15) 2021 